\title{
A prototipagem virtual e a avaliação do design de produtos: Estudo comparativo entre protótipos
}

\section{Virtual prototyping and product design evaluation: Comparative study between prototypes}

\author{
Christianne Soares Falcão \\ Doutora em Design \\ Docente no Departamento de \\ Arquitetura e Urbanismo, \\ Universidade Católica de \\ Pernambuco, Brasil \\ Christiannefalcao.arq@gmail.com
}

\section{Marcelo Marcio Soares}

Ph.D. in Ergonomics

Docente no Departamento de Design da Universidade Federal de Pernambuco, Brasil

soaresmm@gmail.com
RESUMO:

A avaliação de produtos representa uma atividade essencial no ciclo de design ao buscar uma maior satisfação do usuário e, consequentemente, o sucesso do produto no mercado. Para tal, torna-se fundamental a colaboração e a comunicação eficiente entre os diversos membros da equipe. Este artigo tem como objetivo investigar o potencial da prototipagem virtual na avaliação do design de produtos a partir de um estudo comparativo entre protótipos. Como resultado, foi apontada a viabilidade da aplicação do protótipo virtual, correspondendo a uma importante contribuição para as pesquisas no campo da representação gráfica do design de produtos.

Palavras-chave: protótipo virtual; protótipo físico; prototipagem rápida.

\section{ABSTRACT:}

Product evaluation represents an essential activity in the design cycle when seeking greater user satisfaction and, consequently, the product success in the market. To this end, collaboration and efficient communication among team members is essential. This article aims to investigate the potential of virtual prototyping in evaluating product design from a comparative study between prototypes. As a result, the feasibility of applying the virtual prototype was pointed out, corresponding to an important contribution to research in the field of graphic representation of product design.

Keywords: virtual prototype; physical prototype; rapid prototyping. 


\section{INTRODUÇÃO}

No ciclo de design de produtos, a comunicação entre os diversos integrantes da equipe, assim como potenciais usuários, pode ser prejudicada por muitos não conseguirem entender a linguagem utilizada por designers na representação do conceito do produto, sendo esta tradicionalmente realizada a partir de desenhos técnicos, esboços e mock-up físico (ULRICH; EPPINGER, 2008). Na atualidade, para atender a esta demanda, considerando que usuários não são designers, novas ferramentas tecnológicas são desenvolvidas, modificando o cenário de interação nos testes com produtos.

Por outro lado, tem se intensificado a demanda por projetos e restrições quanto ao tempo e eficiência no desenvolvimento de produtos, surgindo novos desafios para diminuição do tempo necessário na construção de protótipos (SISCA, MOGAN; SUBRIN, 2008). Sendo assim, versões digitais para a modelagem e simulação de produtos vêm sendo utilizados por empresas para apresentar novos produtos e permitir que usuários os avaliem. Esta prática é conhecida como prototipagem virtual.

A prototipagem virtual vem apresentando um alto nível de realismo nas representações visuais a partir do desenvolvimento de algoritmos e ferramentas de software, permitindo a interação com modelos complexos de objetos e ambientes que são processados de forma realística e em tempo real (BORDEGONI; FERRISE, 2013). Neste contexto, para uma melhor compreensão do tema abordado, é importante esclarecer as definições de protótipo e prototipagem. Protótipo é o modelo do produto, enquanto que prototipagem é o processo de construção e teste de protótipos.

O uso de protótipos virtuais no design e desenvolvimento de produtos tem acontecido desde a década de 70 (BINNARD, 1999). Conforme Zorriassatine et al. (2003), um protótipo virtual para ser efetivo não pode ser realizado sem a utilização de modelos tridimensionais, especialmente no design mais detalhado. As recentes inovações permitem que a prototipagem virtual seja uma ferramenta mais acessível aos designers, um recurso que anteriormente só era concedido às empresas de grande porte.

Contudo, a qualidade das representações tridimensionais vai depender do nível de precisão dada na construção do protótipo virtual. Para alcançar protótipos virtuais precisos é necessário ter um elevado nível de detalhes para que possuam as mesmas características de um modelo físico correspondente. A precisão em prototipagem depende da simulação fiel de todos os fatores que representam o produto e o seu ambiente operacional, sendo estes a geometria do produto, funções e desempenho, assim como a tecnologia de fabricação pretendida e os participantes humanos e a sua interação com o produto. (ZORRIASSATINE et al. 2003).

Diante deste cenário, este artigo tem como objetivo avaliar a possibilidade de aplicação de protótipos virtuais na avaliação de produtos a partir de um estudo comparativo entre protótipos físico e virtual. As limitações no uso das tecnologias em ambientes virtuais pelos designers, demonstram a 
necessidade de estudos práticos para avaliar possibilidades de aplicação destas.

\section{PROTÓTIPOS E PROTOTIPAGEM}

Dependendo do campo em que for aplicado, diferentes definições podem ser atribuídas ao protótipo, podendo também variar o seu significado de acordo com a área profissional. $\mathrm{Na}$ arquitetura, por exemplo, este é conhecido como o modelo de um edifício em escala reduzida, equanto que o designer de produto o representa na escala real e com mesmo material e funcionalidades. Já os desenvolvedores de softwares criam protótipos modelos a partir de outros softwares semelhantes para em seguida criarem novas versões.

Beaudouin-Lafon e Mackay (2003), definem protótipo como uma representação concreta de uma parte ou da totalidade de um sistema interativo. Trata-se de um artefato tangível e não uma descrição abstrata que exige interpretação. Designers, assim como desenvolvedores, clientes e usuários finais podem utilizar este artefato para visualizar e refletir sobre o projeto. Como parte importante do design, permite uma avaliação inicial do produto, permitindo vários tipos de testes, tais como testes de usabilidade e respostas do usuário quanto as suas preferências de produto. Por outro lado, ajuda o designer a capturar e gerar ideias, apoiando a criatividade.

Neste panorama, a comunicação da equipe de desenvolvedores e usuários é facilitada pelo protótipo, permitindo o debate entre as diversas opções de projeto, sendo uma importante ferramenta para obter o feedback dos fornecedores, vendedores e gestão. Preece, Rogers e Sharp (2002), descrevem uma experiência com protótipos interessante realizada por Ehn e Kyng $^{1,}$ no qual uma caixa de papelão com a etiqueta "Desktop Laser Printer" é utilizada como um mockup. Em sua configuração, a impressora não era real, mas isso não importava, pois o objetivo era que os usuários pudessem experimentar e visionar o que seria ter uma destas máquinas em suas mesas de trabalho. Isto pode parecer um exagero, mas em 1982, quando este experimento foi feito, uma impressora laser de mesa era um equipamento extremamente caro e não era comumente vista em um escritório.

Conforme observado por Vasconcelos (2015), o termo protótipo no Design é interpretado de forma livre como uma representação aproximada de um produto, possibilitando a interação com usuários para a avaliação. Este pode ser simplesmente a construção de um cenário de papel (storyboard), um mockup de papelão ou um modelo de espuma, até um protótipo físico funcional aproximado de um produto final. Neste contexto, o protótipo e a técnica de prototipagem podem ser analisados conforme as seguintes dimensões porpostas por Beaudouin-Lafon e Mackay (2003):

\footnotetext{
${ }^{1}$ Ehn, P.; Kyng, M. 1991. Cardboard computers: mocking-it-up or hands-on the future. In J. Green-baum and M. Kyng (eds.). Design at Work. Hills-dale, NJ: Lawrence Erlbaum Associates.
} 
- Precisão descreve o nível de detalhamento conforme a finalidade do protótipo;

- Representação descreve a forma do protótipo que pode ser física ou virtual;

- Interatividade descreve a extensão na qual o usuário pode interagir com o protótipo, que pode ser apenas visualizar ou interagir com o mesmo;

- Evolução descreve o ciclo de vida esperado do protótipo.

\subsection{Precisão}

O nível de precisão de um protótipo é definido conforme o nivel de detalhamento em que foi construído, como por exemplo, esboços e croquis, mesmo sendo gerados em computador, tendem a não serem precisos. Conforme o grau de precisão da aparência e interação do produto, os protótipos podem ser divididos em baixa, média e alta fidelidade.

Os protótipos de baixa fidelidade são construídos rapidamente para descrever conceitos e alternativas de design e proporcionam pouca ou nenhuma funcionalidade. Estes são desenvolvidos com materiais bem diferentes do que se intenciona para a versão final, tal como papel e papelão, para demonstrar a aparência geral do produto em desenvolvimento e para se comunicar e trocar ideias com os usuários. Correspondem a uma alternativa simples, rápida e de baixo custo, particularmente importante nos primeiros estágios de desenvolvimento do produto e, por serem flexíveis encorajam a exploração de ideias e modificações. (PREECE, ROGERS; SHARP, 2002).

Os protótipos de média e alta fidelidade são inteiramente interativos dependendo do grau de precisão, simulando muitas das funcionalidades do produto final. Os protótipos de média fidelidade simulam parcialmente a interação do sistema e funcionalidade, enquanto que os de alta fidelidade representam fielmente a interface do produto. (VASCONCELOS, 2015). Conforme Preece, Rogers e Sharp (2002), o protótipo de alta fidelidade envolve um custo bem maior para seu desenvolvimento, sendo útil para a venda da ideia e para testes técnicos, enquanto que o protótipo de baixa fidelidade deve ser encorajado nas questões de exploração do conteúdo e estrutura. Sendo assim, a forma do protótipo deve ser adaptada ao nível de precisão desejado e de acordo com o que se pretende avaliar a medida que o projeto se desenvolve.

\subsection{Representação}

A representação do protótipo pode ser física ou virtual, permitindo ao designer adquirir conhecimento a partir da interação com o mesmo, como também analisar a interface com o usuário.

O protótipo físico pode ser construído a partir de vários materiais, tais como madeira, argila, espuma ou metal e não precisa necessariamente possuir as mesmas propriedades do produto final (ZORRIASSATINE et al, 2003; 
JIMENO; PUERTA, 2007), como também pode representar uma amostra exata do produto final.

Conforme Zorriassatine et al. (2003), os protótipos físicos podem ser classificados em três grupos principais, de acordo com a natureza da mudança física utilizada na sua construção, conforme descritos a seguir:

1. Protótipos tradicionais. São tradicionalmente construídos com a remoção de material a partir de uma variedade de processos de um bloco inicial. Os métodos e processos de fabricação mais adequados ou convenientes podem ser usados em qualquer combinação para criar os protótipos, sendo estes, totalmente manual utilizando ferramentas manuais, uma combinação de manual com o auxílio de máquinas para operar dispositivos como perfuração e torno, ou inteiramente automatizado a partir de máquinas de controle numérico por computador.

2. Prototipagem rápida. Esta tecnologia corresponde a um modelo tridimensional do design requerido criado no computador. Em seguida, o modelo é convertido para um formato digital referido como STL2 (Stereolithography Tessellation Language) e o modelo final é construído a partir da junção das diversas camadas, geradas a partir do arquivo STL.

3. Prototipagem Híbrida. Esta tecnologia combina as técnicas utilizadas na prototipagem rápida (adição de material) com o sistema de máquinas de controle numérico por computador (subtração de material), cuja finalidade consiste em moldar as peças com maior precisão. 0 processo de planejamento para prototipagem híbrida é mais complicado que os dois primeiros por envolver dois tipos de tecnologias ao mesmo tempo, mas por outro lado podem proporcionar uma melhor precisão e processar o material conforme pretendido para incorporação no produto acabado.

Dependendo do método de construção, os protótipos físicos podem apresentar algumas limitações, como por exemplo, não permitem a variação de formas e materiais e a sua produção pode ser demorada e ter custos elevados. A prototipagem rápida pode se apresentar como método mais vantajoso quanto ao tempo e custos, mas por outro lado pode ficar aquém quanto ao acabamento da superfície.

Outro fator importante é que ao utilizar protótipos físicos na revisão do design de produtos é muito difícil ou mesmo impossível modificá-los. Este fator dificulta extensivos testes com diferentes possibilidades e dificulta a inovação e a inspiração de novas ideias de design, pois cada protótipo individual incorre em um custo adicional (ZORRIASSATINE et al., 2003), em

\footnotetext{
${ }^{2}$ STL é um formato de arquivo nativo para software CAD e é suportado por muitos outros pacotes de software, sendo amplamente utilizado para prototipagem rápida. Arquivos STL descrevem apenas a geometria da superfície de um objeto tridimensional, sem qualquer representação de cor, textura e outros atributos comuns ao modelo CAD.
} 
consequência muitas empresas deixam para utilizá-lo nas últimas fases do processo de design e tem buscado como alternativa o protótipo virtual.

O protótipo virtual (PV) pode ser definido como a construção no computador de modelos de produtos em um ambiente virtual (JIMENO; PUERTA, 2007). Tomando como base diversos estudos, Wang (2002), descreve protótipo virtual como uma simulação em computador de um produto físico que pode ser apresentado, analisado e testado a partir dos aspectos do ciclo de vida do produto como se fosse em um modelo físico real. Esta ferramenta permite a equipe de projeto avaliar a qualidade estética e as características funcionais de um produto antes da construção do produto físico (BORDEGONI; FERRISE, 2013).

Uma das maiores vantagens da prototipagem virtual corresponde a sua natureza digital, que juntamente com a capacidade de processamento do computador, permite a geração de várias alternativas de concepção do produto sem muito esforço, uma vez que o primeiro protótipo é desenvolvido, como também a revisão e otimização das funcionalidades do objeto de forma mais rápida, econômica e eficiente (ZORRIASSATINE et al., 2003).

Apesar das vantagens, em algumas ocasiões um protótipo virtual é menos preferível em comparação a um protótipo físico. Liu (2011) cita como exemplo a preferência de muitos participantes em interagir com um protótipo físico nos testes sobre os aspectos ergonômicos de um produto. Desta forma, tanto os protótipos físicos quanto os virtuais têm papeis importantes para o design. Com base nestas proposições, a prototipagem é um processo interativo e os dois tipos de tecnologias não são estritamente competitivos, onde os pontos fortes e as vantagens de um abordam a fragilidade e limitações do outro. Sendo assim, cada tipo de protótipo fornece informações sobre alguns aspectos e ignoram outros e cabe ao designer escolher a representação mais adequada ao propósito da avaliação (BEAUDOUIN-LAFON; MACKAY, 2003), ou unir ambas as técnicas para formar uma poderosa ferramenta para o desenvolvimento de produtos mais complexos. (CAMPBELL et al., 2004).

\subsection{Interatividade}

A interatividade corresponde a forma como o usuário pode interagir com o protótipo. Nos protótipos virtuais, a interação baseia-se principalmente na visão, no entanto a interação fornecida pelos protótipos não devem limitarse apenas a este sentido, visto que a interação com produtos é realizada tanto visualmente como de forma tátil. Embora a interação com protótipos físicos proporcione uma interface de toque mais natural, no que aumenta o realismo, os protótipos virtuais podem oferecer facilidades para explorar diferentes estratégias de interação pela flexibilidade em ser readaptado para as diferentes versões do projeto (BORDEGONI et al., 2009; BARBIERI et al., 2013).

Bordegoni et al. (2009) apontam uma situação a partir da fusão entre um protótipo físico e um virtual (protótipo misto) para testes. A prototipagem mista é baseada na mistura de componentes reais e virtuais em um ambiente de realidade mista em que a aparência visual do produto é sobreposta em um 
mock-up físico. Esta técnica vem apresentando soluções mais efetivas para a avaliação de produtos interativos em relação a protótipos totalmente reais ou totalmente virtuais, pelo fato de combinar as vantagens da prototipagem virtual (avaliação rápida das várias alternativas de design) e a prototipagem física (que envolve o sentido do tato), permitindo uma sensação de toque mais realista dos objetos virtuais pelo usuário. Um exemplo de aplicação foi sugerido por Barbieri et al. (2013), conforme ilustra a Figura 1. Neste estudo foi realizado um teste comparativo da usabilidade em três diferentes máquinas de lavar roupas a partir de um protótipo físico representando os botões de operação da máquina e sobre este foi projetado o protótipo virtual.

Figura 1: Exemplo de prototipagem mista em produtos.

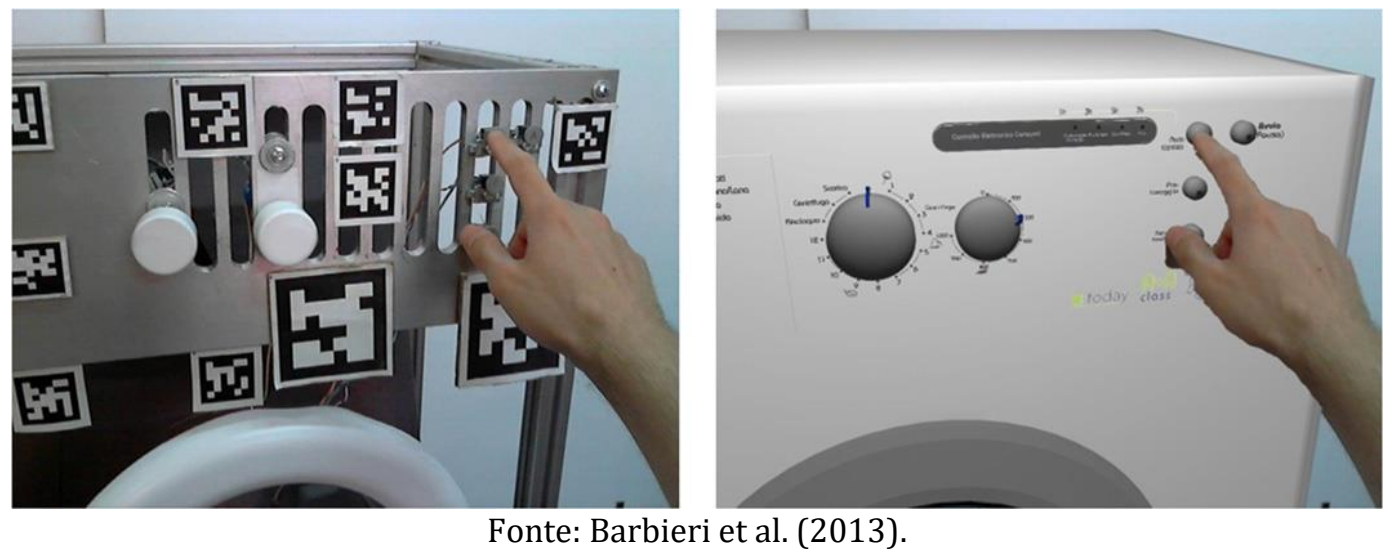

\subsection{Evolução}

O ciclo de vida do protótipo possui diferentes períodos, a prototipagem rápida, por exemplo, geralmente é utilizada nas fases iniciais do ciclo de design por ser mais fácil de produzir e com menor custo, visto que o objetivo consiste em explorar rapidamente vários tipos de interação e em seguida são descartados. Os protótipos interativos são desenvolvidos quando o projeto está em andamento com o objetivo de evoluir para as próximas fases. Dificilmente os protótipos físicos suportam esse comportamento interativo, sendo o protótipo virtual mais vantajoso pela sua flexibilidade e mutabilidade (BARBIERI et al., 2013).

\section{METODOLOGIA}

Para o estudo de caso proposto neste artigo, duas fases foram desenvolvidas: Fundamentação e Avaliação, conforme apresentado na figura 2 . 
Figura 2: Distribuição das duas fases do estudo de caso.

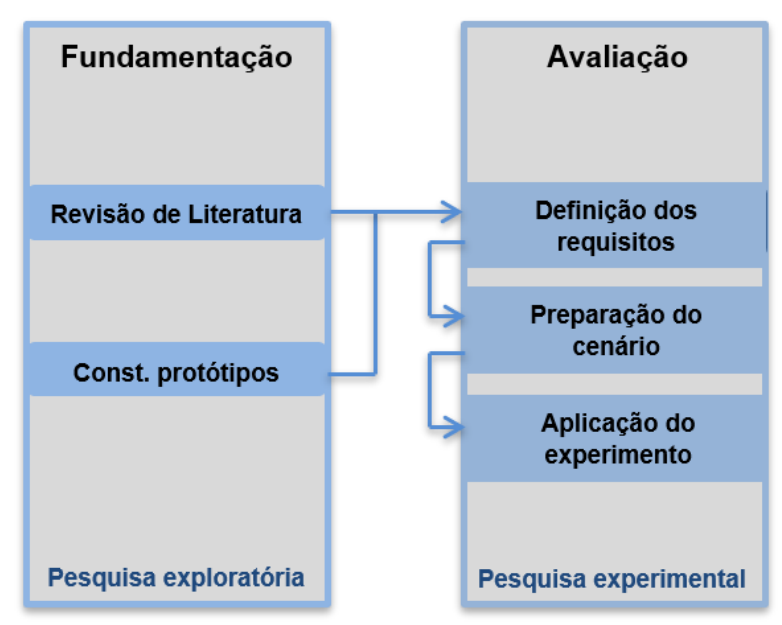

Fonte: Os autores.

A primeira fase compreendeu a contextualização dos temas protótipo e prototipagem com base na revisão de literatura e construção dos modelos utilizados no experimento. A segunda fase consistiu na análise com dois tipos de protótipos (um virtual e um físico) e a aplicação de um questionário de avaliação da experiência do usuário e estudo comparativo entre os protótipos. O objetivo desta fase da pesquisa consistiu em verificar as seguintes questões:

- Os testes com protótipos virtuais podem auxiliar designers na avaliação de produtos?

- Os testes com protótipos virtuais permitem ao usuário ficar envolvido com a atividade de avaliação?

\subsection{Construção dos protótipos}

Primeiramente o protótipo virtual foi elaborado objetivando mostrar claramente algumas características estéticas e de detalhamento, enfatizando os benefícios de um protótipo virtual ainda nas primeiras fases de desenvolvimento do produto. Conforme descrito no item 2, o protótipo foi construído a partir das seguintes especificações:

Precisão. 0 protótipo foi desenvolvido com base em um modelo de rádio relógio existente no mercado, seguindo fielmente as mesmas dimensões do produto real. Para atender ao objetivo do estudo que consistia em avaliar a volumetria e a disposição dos botões do rádio relógio, foi elaborado um protótipo forma, ou seja, não simulam as funções do produto e nem a aparência exata, mas representam a volumetria real. Neste contexto, podemos classificar o protótipo como sendo de média fidelidade.

Representação. 0 protótipo foi totalmente desenvolvido no computador utilizando o software de modelagem 3D SolidWorks ${ }^{3}$, no que o caracteriza como um protótipo virtual. A Figura 3 ilustra o modelo na tela do software.

${ }^{3}$ https://www.solidworks.com/ 
Figura 3: Exemplos de dispositivos para manipulação de objetos tridimensionais.

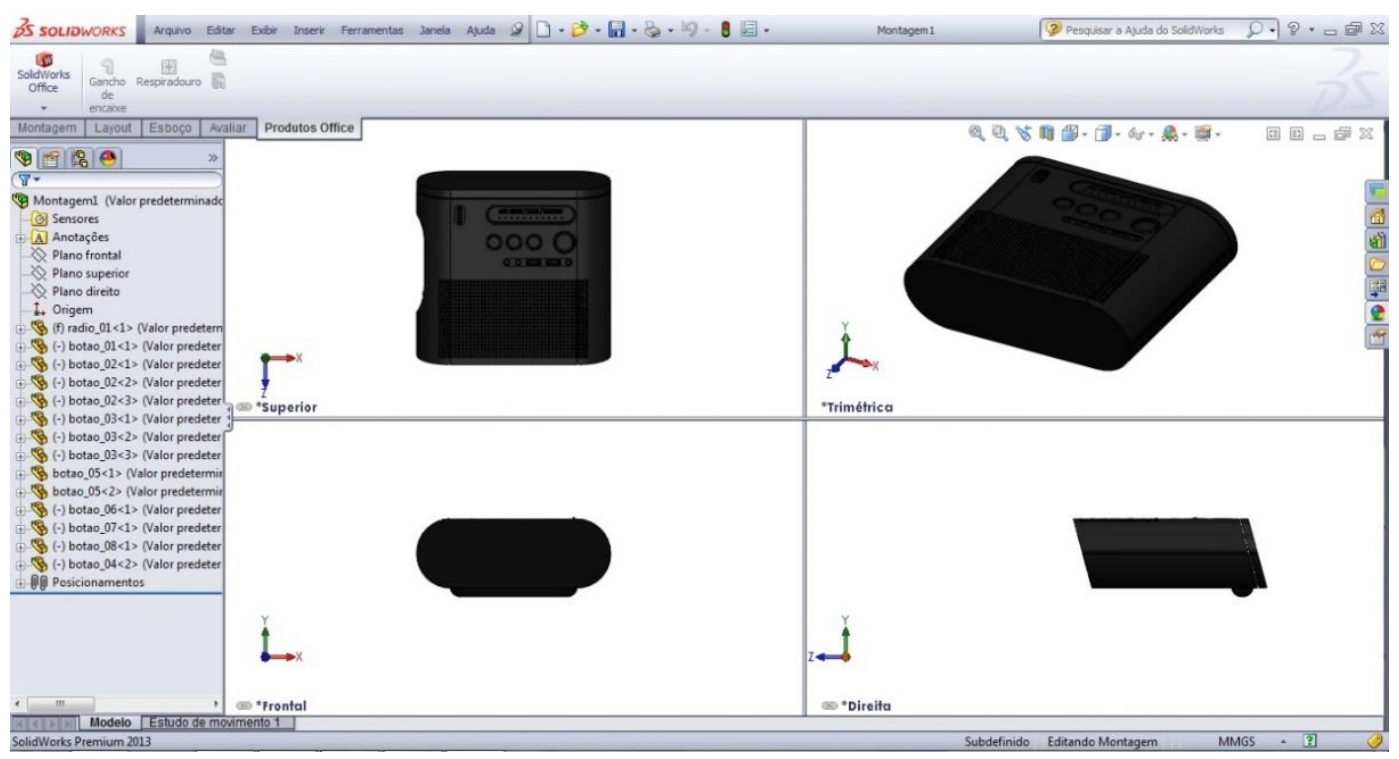

Fonte: Os autores.

Interatividade. A interação com o modelo consiste em um usuário real utilizando um protótipo virtual, a partir dos seguintes sentidos: visual, a partir da visualização do protótipo projetado na tela, e o tátil, para movimentação do modelo com o auxílio de um dispositivo háptico. 0 software de modelagem utilizado permite que o usuário movimente o modelo através de atalhos que identificam as faces da peça. É possível rotacionar o modelo, modificar a transparência, as formas de visualização, o material e a cor. modificado.

Evolução. 0 protótipo foi desenvolvido em CAD e pode ser facilmente

Dando continuidade à construção dos protótipos, a segunda etapa consistiu na montagem do protótipo físico. 0 modelo foi desenvolvido objetivando os benefícios da prototipagem rápida a partir do protótipo virtual. As seguintes especificações correspondem ao protótipo físico:

Precisão. Como foi desenvolvido com base no modelo virtual, este também é classificado como de média fidelidade, apresentando a volumetria em tamanho real do produto, mas com reduzido nível de funcionalidade. Desta forma, o modelo desenvolvido foi caracterizado como um protótipo forma, no qual permitia a avaliação da volumetria do objeto em escala real, assim como a disposição dos botões e localização do display, porém os botões não podiam ser acionados.

Representação. 0 protótipo foi impresso na impressora 3D tipo FDM, modelo uPrint, no que o caracteriza como um protótipo físico de prototipagem rápida. 0 modelo foi dividido em várias partes para impressão, que foram encaixadas para compor a volumetria final, conforme ilustra a Figura 4. Após o encaixe e colagem das partes, o modelo recebeu pintura automotiva spray na cor preta, conforme Figura 5. 
Figura 4: Divisão do modelo em diversas partes para impressão 3D e montagem do modelo final.
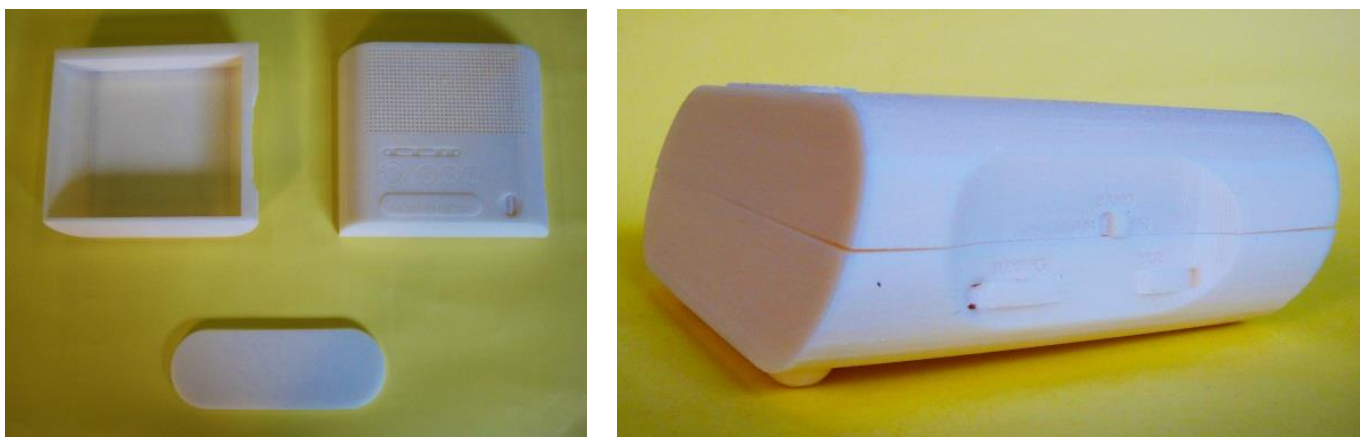

Fonte: Os autores.

Figura 5: Vistas do protótipo físico final.
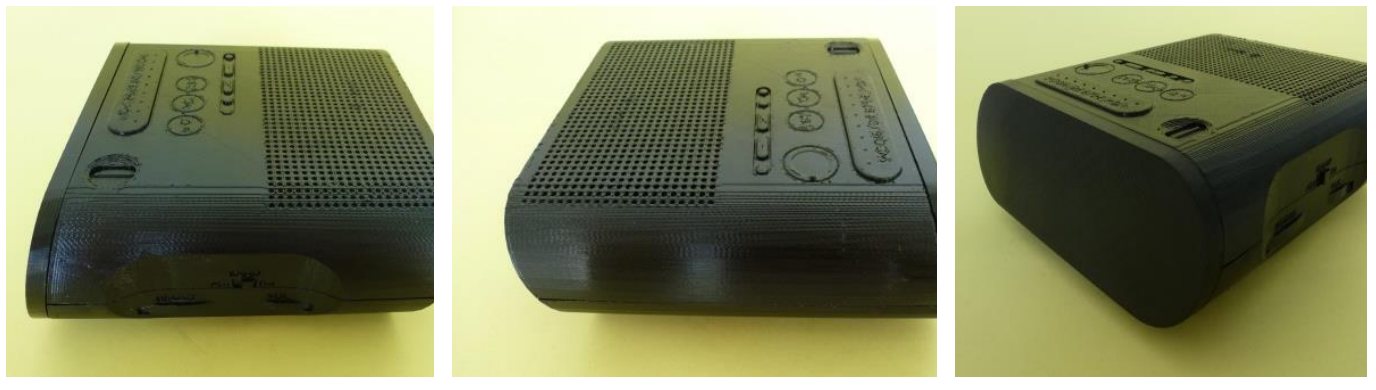

Fonte: Os autores.

Interatividade. A interação com o modelo consiste em um usuário real utilizando um protótipo físico, a partir dos seguintes sentidos: visual, a partir da visualização do volume físico real, e o tátil, para movimentação do modelo diretamente com as mãos.

Evolução. O protótipo foi impresso a partir da tecnologia de prototipagem rápida e não pode ser modificado após a colagem e pintura das peças. Qualquer modificação deverá ser realizada no modelo CAD e novamente impresso.

\section{ESTUDO COMPARATIVO ENTRE PROTÓTIPOS}

A partir da revisão de literatura, um conhecimento básico sobre testes de produtos com protótipos foi adquirido para elaboração deste estudo. Como o foco principal do experimento consistia em investigar a possibilidade de avaliação do produto pelo usuário utilizando os dois tipos de protótipos, as questões foram direcionadas para que o usuário descrevesse a sua experiência com cada protótipo.

Considerando que todos os sujeitos são de alguma forma potenciais consumidores de produtos, não houve restrições para a escolha dos participantes. 0 experimento foi realizado com 15 alunos da graduação do curso de design pertencentes a diversos períodos, que estavam cursando a 
disciplina Ergonomia e Usabilidade de Produtos e Sistemas. Os participantes foram identificados a partir de um número e a sua quantidade foi estipulada a partir dos estudos de Macefield (2009), no qual determinava um grupo de 825 participantes para obter resultados estatisticamente significativos.

\subsection{Preparação do cenário}

O primeiro cenário consistiu no experimento com o protótipo virtual. Para tal, foi utilizado o modelo virtual do rádio relógio construído conforme as etapas descritas no item 3.1. Na construção do modelo as características estéticas foram evidenciadas para enfatizar os benefícios do protótipo virtual na avaliação pelo usuário, ou seja, conforme a revisão de literatura e os resultados do questionário do item anterior, o protótipo virtual oferece maiores vantagens na avaliação estética quando comparado ao protótipo físico.

Para a interação com o usuário em ambiente virtual, foi utilizado o software eDrawing ${ }^{4}$, conforme Figura 6. A escolha pelo software se deu em razão da facilidade de importar o arquivo do protótipo virtual gerado no software SolidWorks, como também possuir um aplicativo para iPad, que consistiu no dispositivo de hardware utilizado.

Figura 6: Protótipo virtual do rádio relógio visualizado na tela do iPad a partir do software eDrawings.

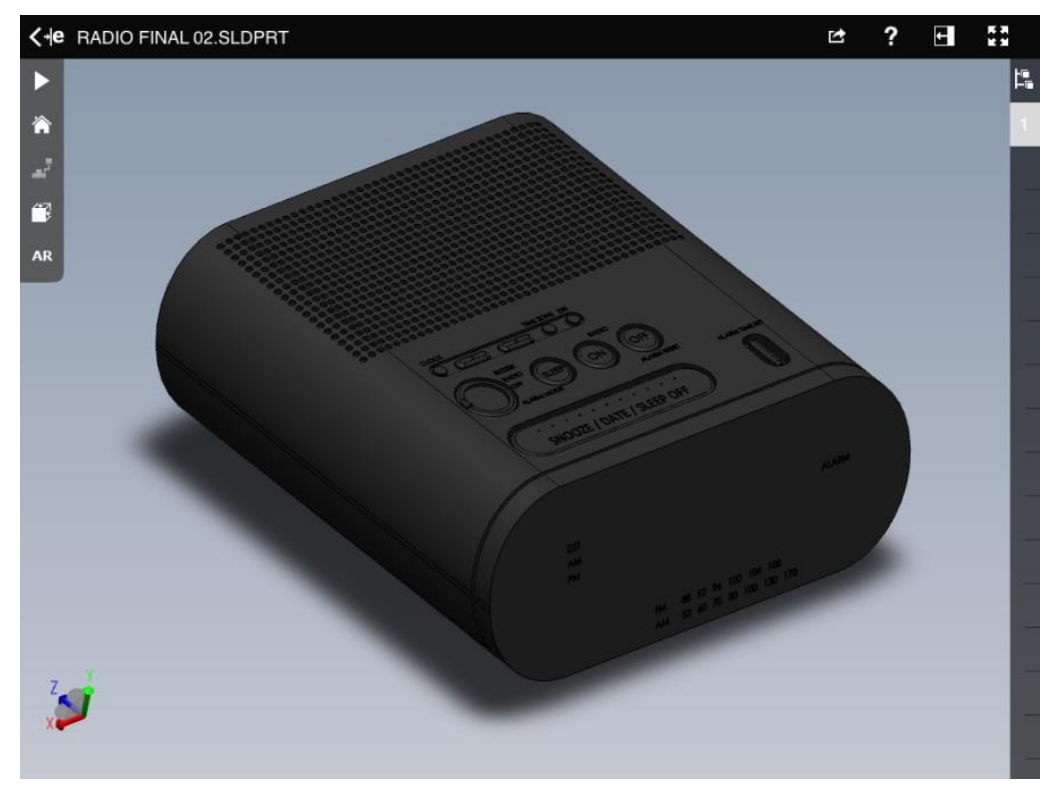

Fonte: Os autores.

O segundo cenário consistiu no experimento com o protótipo físico. No entanto, o modelo impresso não possuía as indicações das funções de cada botão, conforme o modelo virtual. Desta forma, foram colocadas etiquetas indicativas para que os usuários pudessem identificar as funções de cada botão, conforme Figura 7.

\footnotetext{
${ }^{4}$ http://www.edrawingsviewer.com/
} 
Figura 7: Protótipo físico com as etiquetas indicativas dos botões do menu.

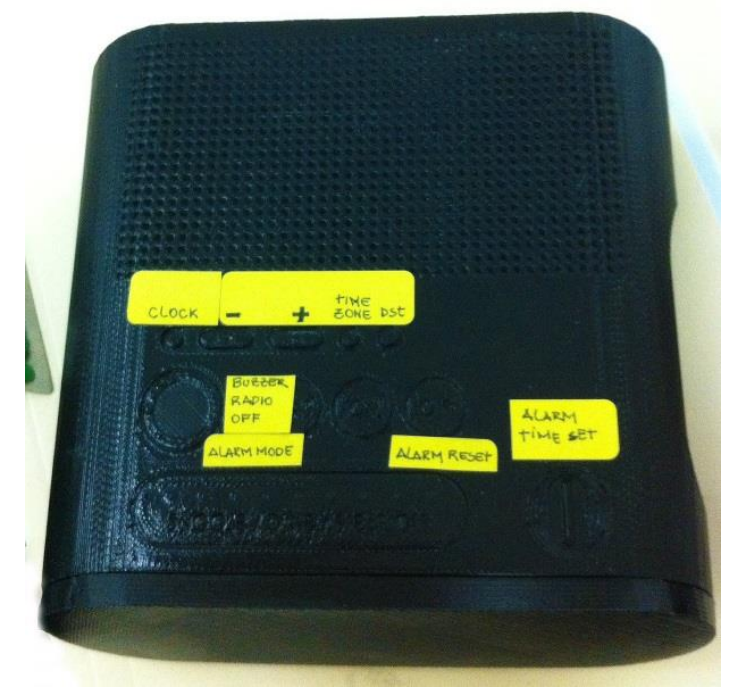

Fonte: Os autores.

Ao final do experimento, os participantes reponderam a um questionário. Na primeira parte foram coletados dados referentes ao participante, a partir de questões abertas, e a sua experiência anterior com rádio relógio e testes com protótipos virtuais, a partir de questões de múltipla escolha Sim/Não. Nenhum dado pessoal que identificasse a identidade do participante foi coletado.

A segunda parte correspondeu à avaliação da experiência do usuário com os protótipos virtual e físico. Primeiramente o usuário avaliou o protótipo virtual e respondeu as quatro questões referentes ao mesmo. Somente ao finalizar esta etapa, o protótipo físico era apresentado para também ser avaliado da mesma forma que o virtual. Ao finalizar as duas análises, o usuário era convidado a responder a um estudo comparativo dos dois protótipos. As duas questões desta sessão foram de múltipla escolha e os participantes só poderiam escolher uma das alternativas. Por fim, os participantes foram convidados a avaliar sobre os procedimentos adotados no teste a partir de uma escala de diferencial semântico, com as extremidades difícil/fácil de seguir, como também tecerem seus comentários e sugestões de forma aberta.

\subsection{Processo do experimento}

0 experimento foi iniciado após o cenário da pesquisa ter sido concluído. $\mathrm{O}$ horário foi previamente agendado com os participantes conforme a disponibilidade de cada um. Cada participante foi recebido pelo pesquisador, que explicava os procedimentos a serem realizados no teste. Logo após, o participante era convidado a ler o termo de consentimento em meio eletrônico (iPad). Ao concordar com a participação, a continuidade do experimento seguia as seguintes etapas: 
a. O participante preenchia a primeira parte do questionário com seus dados.

b. O moderador entregava o iPad e apresentava o protótipo virtual. 0 participante poderia analisar o protótipo livremente.

c. Após análise, o participante seguia o passo-a-passo das seguintes tarefas: 1 . Ajuste da hora; 2 . Ajuste do alarme e 3. Desligar o alarme. 0 protótipo era analisado a partir da simulação em ambiente virtual das tarefas sugeridas.

d. Ao concluir a análise, o participante preenchia as questões referentes ao protótipo virtual.

e. 0 mesmo procedimento era aplicado com o protótipo físico.

f. Ao concluir o experimento com os dois protótipos, o participante respondia as duas perguntas referentes a comparação entre protótipos, e por fim, a avaliação pós-teste.

Para realização do experimento, os participantes levaram em média 10 minutos para concluir todas as etapas propostas.

\subsection{Resultados do experimento}

A idade dos participantes variava entre 18 e 28 anos e nove (9) dos participantes pertenciam ao sexo feminino, enquanto que seis (6) pertenciam ao sexo masculino.

No item sobre a experiência do usuário em já ter utilizado um rádio relógio anteriormente, dez (10) responderam que sim e apenas cinco (5) responderam que não. Na pergunta seguinte relacionada a experiência com testes com protótipos virtuais, apenas cinco (5) responderam que sim e os outros dez (10) responderam que não. Apesar dos resultados coincidirem, as respostas dos participantes não foram coincidentes, ou seja, nem todos que tiveram experiência com um rádio relógio também tiveram experiência com um protótipo virtual. Desta forma, o critério para separação entre os grupos de usuários foi a partir de sua experiência com protótipos virtuais, foco principal deste estudo. Os participantes foram então divididos em dois grupos: o grupo dos usuários novatos, aqueles que nunca realizaram um teste com protótipo virtual, e o grupo dos usuários regulares, aqueles que já utilizaram um protótipo virtual.

Quanto à avaliação dos protótipos, as duas primeiras questões abordavam a sua experiência com o protótipo, a terceira questão abordava a opinião do usuário quanto a sua eficiência, e por último, o usuário foi convidado a deixar seus comentários ou recomendações sobre o experimento. A Figura 8 demonstra os gráficos com os resultados das três primeiras perguntas de acordo com os dois grupos de usuários. 
Figura 8: Resultados das questões 1, 2 e 3 sobre o protótipo virtual

Questão 1: Como você se sentiu usando o modelo virtual do rádio relógio?

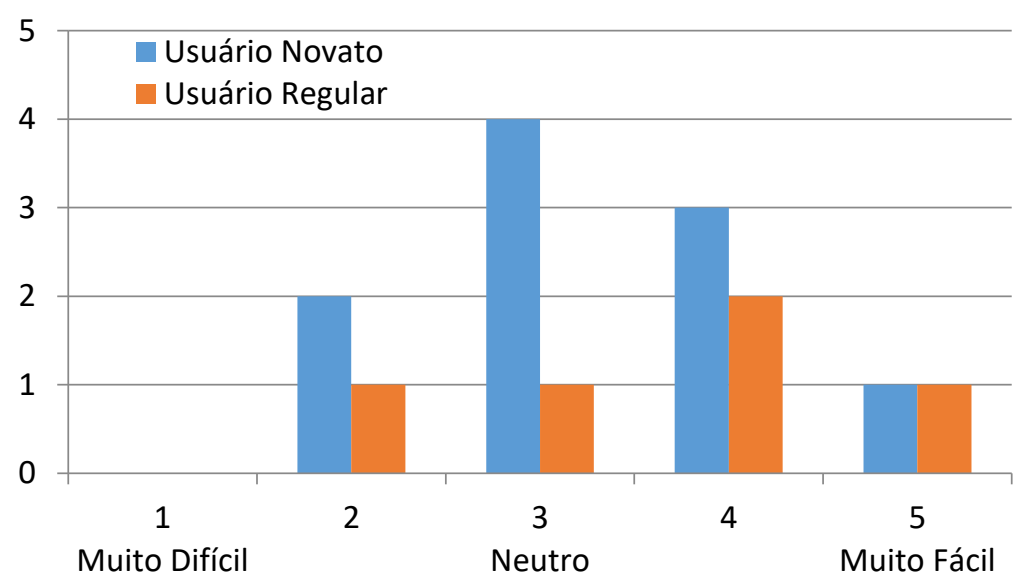

Questão 2: 0 que você achou da visibilidade do modelo virtual do rádio relógio?

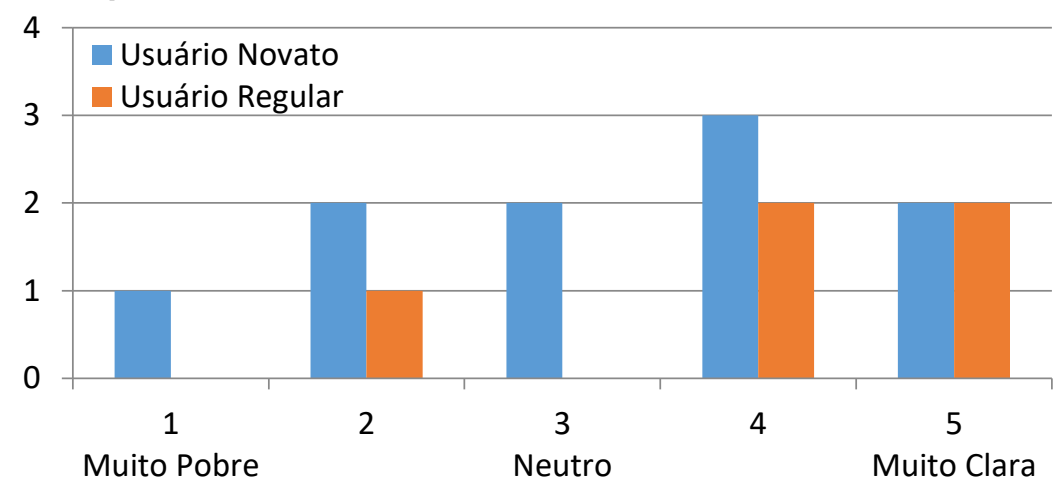

Questão 3: Você acredita que o experimento com o protótipo virtual foi eficiente na avaliação do produto?

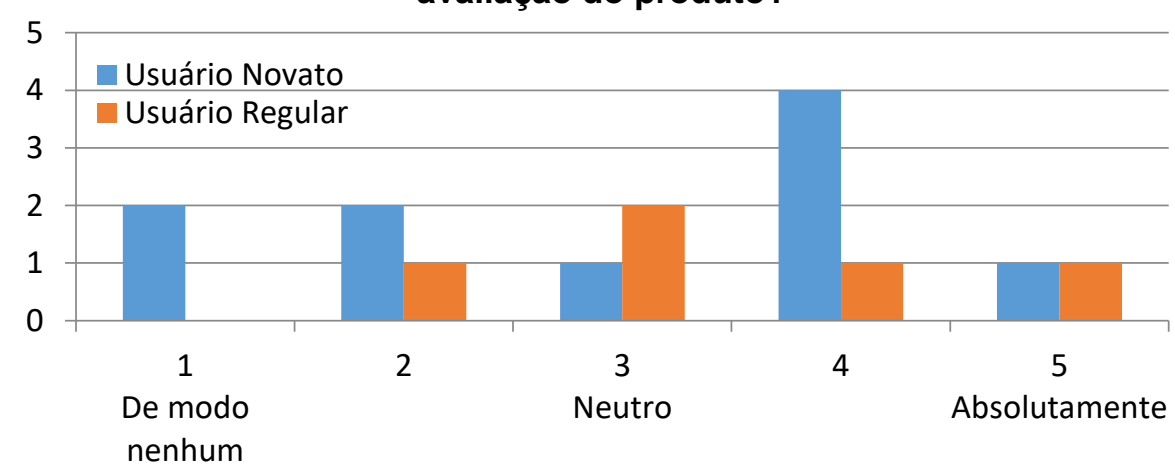

Fonte: Os autores.

Conforme os resultados apresentados, a experiência com o protótipo virtual para o grupo de usuários regulares foi mais fácil do que para os usuários novatos, que optaram na sua maioria pela posição neutra. Neste contexto, podemos identificar uma tendência do usuário novato a não ter parâmetros suficientes para opinar, pois ainda não está familiarizado com o ambiente virtual. 
Quanto ao aspecto visibilidade, os resultados foram positivos e indicaram que os usuários conseguiram visualizar o objeto de forma clara. Por fim, os resultados do último gráfico demonstram que os participantes não se sentiram seguros em afirmar que o protótipo virtual foi eficiente na avaliação, apesar da maioria ter escolhido o nível quatro da escala. Ao analisar o grupo de usuários novatos separadamente, este fator se evidencia, reforçando a hipótese identificada no primeiro gráfico da questão 1.

Na última questão, os usuários foram bastante participativos deixando seus comentários sobre a sua impressão do experimento, no qual foram apontados os seguintes aspectos.

0 grupo de usuários novatos descreveram problemas de usabilidade encontrados na realização das tarefas sugeridas, sendo estes:

- Dificuldades de encontrar os botões;

- Dificuldades de compreensão do funcionamento dos botões;

- Alguns dos botões são muito pequenos.

O grupo de usuários regular argumentaram a necessidade de um protótipo funcional e com opções de feedback para melhorar a interatividade. Provavelmente, por já ter experiência com o uso de protótipos virtuais, os participantes deste grupo sentiram a necessidade de um experimento mais aprofundado, ao contrário dos usuários novatos que se preocuparam apenas em avaliar as questões de usabilidade das configurações do menu, em conformidade com o sugerido no estudo.

No que refere a apresentação do protótipo, os dois grupos apontaram a dificuldade de visualização dos textos indicativos dos botões em consequência da falta de contraste com a cor preta do volume.

Dando prosseguimento ao experimento, o protótipo físico foi avaliado conforme os mesmos procedimentos do protótipo virtual. A Figura 9 demonstra os gráficos com os resultados de acordo com os dois grupos de usuários.

Figura 9: Resultados das questões 5, 6 e 7 sobre o protótipo físico.

Questão 5: Como você se sentiu usando o modelo físico do rádio relógio?

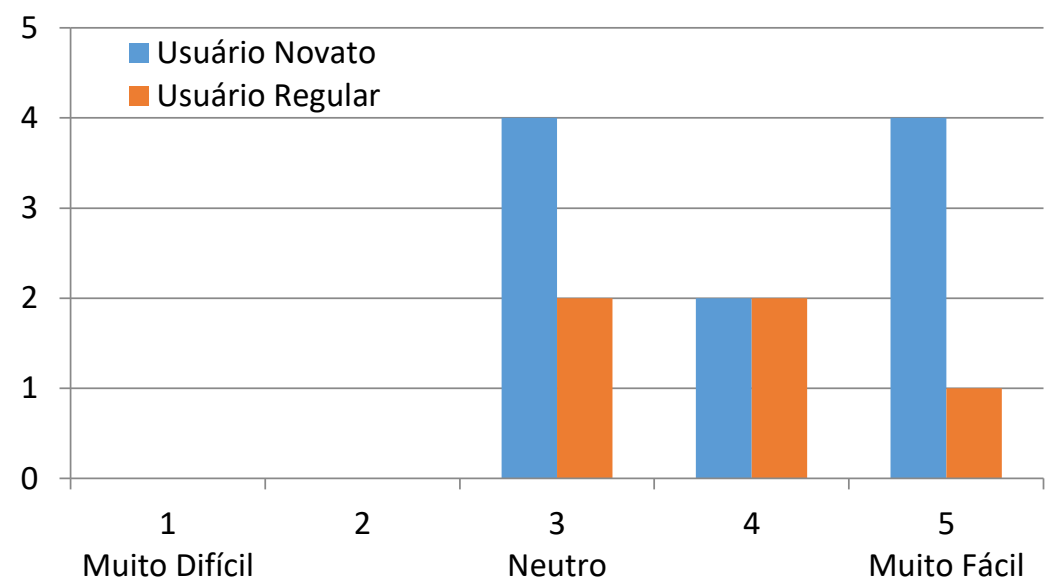


Questão 6: O que você achou da aparência do modelo físico do rádio relógio?

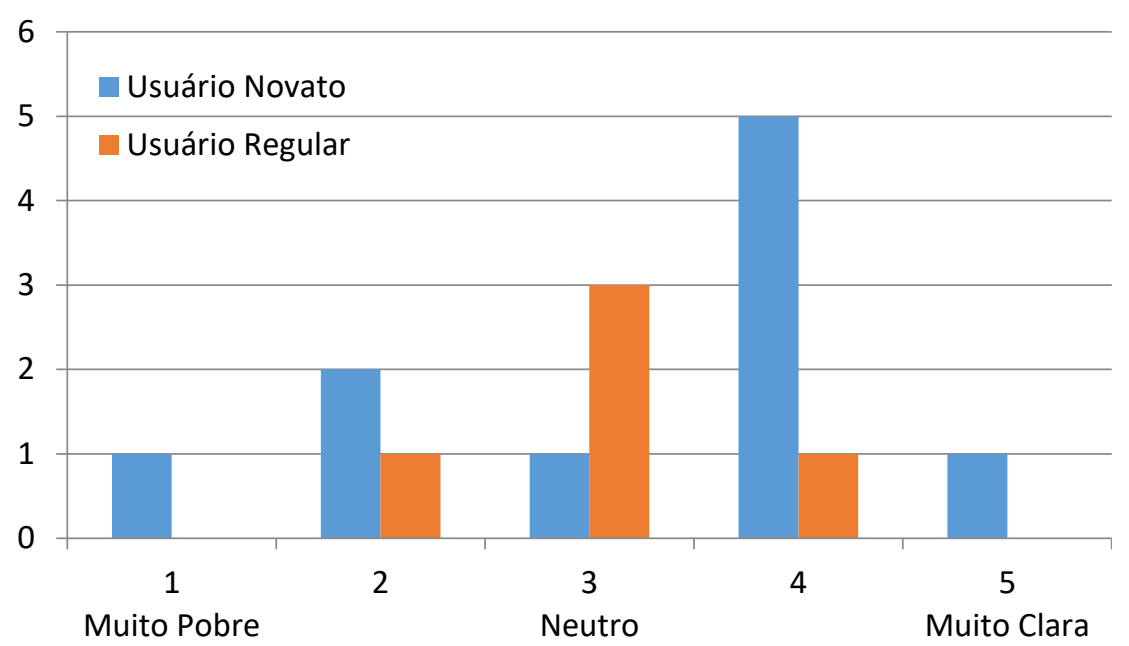

Questão 7: Você acredita que o experimento com o protótipo virtual foi eficiente na avaliação do produto?

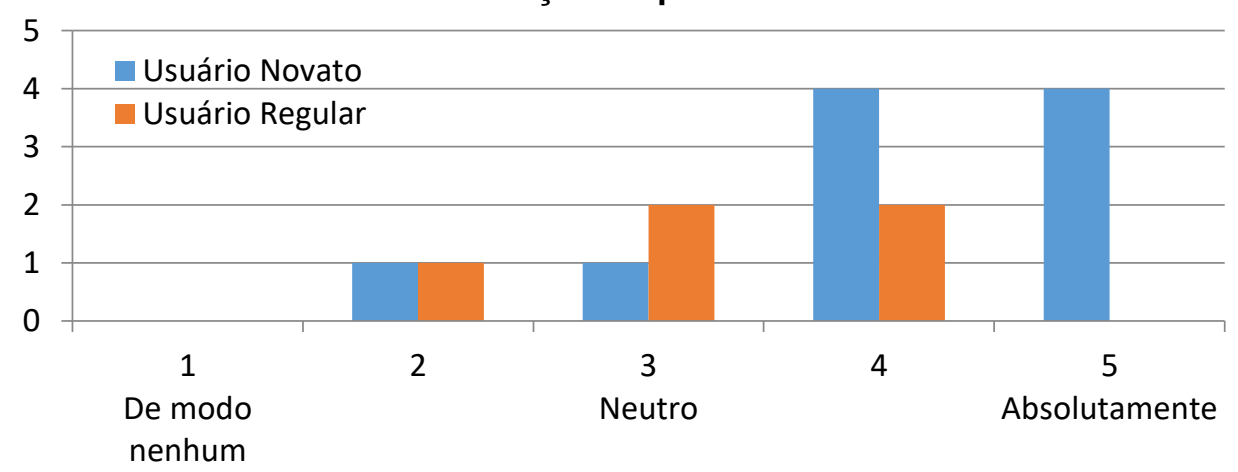

Fonte: Os autores.

No primeiro gráfico sobre a experiência com o protótipo físico, os resultados apresentaram que os participantes estavam seguros em opinar pela facilidade de uso do modelo, ao contrário do que foi observado com o protótipo virtual. Tal fator pode ser explicado pelo fato do protótipo físico representar uma tecnologia bastante consolidada no design de produtos. Este fator é reforçado pela análise dos resultados da questão 7 , na qual os participantes responderam com confiança, e em sua maioria, os níveis quatro e cinco da escala.

Da mesma forma como ocorreu com o protótipo virtual, o quesito visibilidade do protótipo físico também foi avaliado de forma positiva, com algumas restrições que foram indicadas na questão 8, conforme os aspectos a seguir.

Quanto a aparência do protótipo, os dois grupos apontaram que a cor preta e a pintura com brilho dificultaram a visualização dos botões. No grupo de usuários regulares, um dos participantes apontou que a aparência do 
protótipo físico não era tão boa quanto a do virtual, mas sentir as texturas permitiu uma melhor percepção do volume. Este fator foi complementado por outro participante do mesmo grupo, ao afirmar que sentiu maior segurança sobre a atividade realizada com o protótipo físico. A mesma avaliação foi realizada pelo grupo de usuários novatos. Os participantes indicaram que o protótipo físico fornece uma melhor dimensão do produto, sendo mais fácil realizar as tarefas e perceber que usava os botões corretamente.

Quanto as dificuldades encontradas na realização das tarefas sugeridas, um participante de cada grupo de usuários acrescentou que os botões CLOCK/TIME ZONE/DST são muito pequenos e próximos aos botões de ajuste +/-, dificultando a realização da tarefa de ajuste da hora. Estas duas respostas reforçam o pressuposto da avaliação com o protótipo físico permitir uma melhor compreensão da escala real do artefato, como também complementa a identificação dos problemas de usabilidade identificados anteriormente com o protótipo virtual.

Ao concluir o experimento com os dois protótipos, os participantes foram convidados a realizar uma análise comparativa. Na questão 9, os participantes indicaram qual dos dois protótipos foi mais eficiente na avaliação sugerida na pesquisa. Conforme ilustra a Figura 10, nove dos quinze participantes indicaram o protótipo físico como o mais adequado.

Figura 10: Resultado da comparação entre protótipos quanto a eficiência na avaliação sugerida na pesquisa.

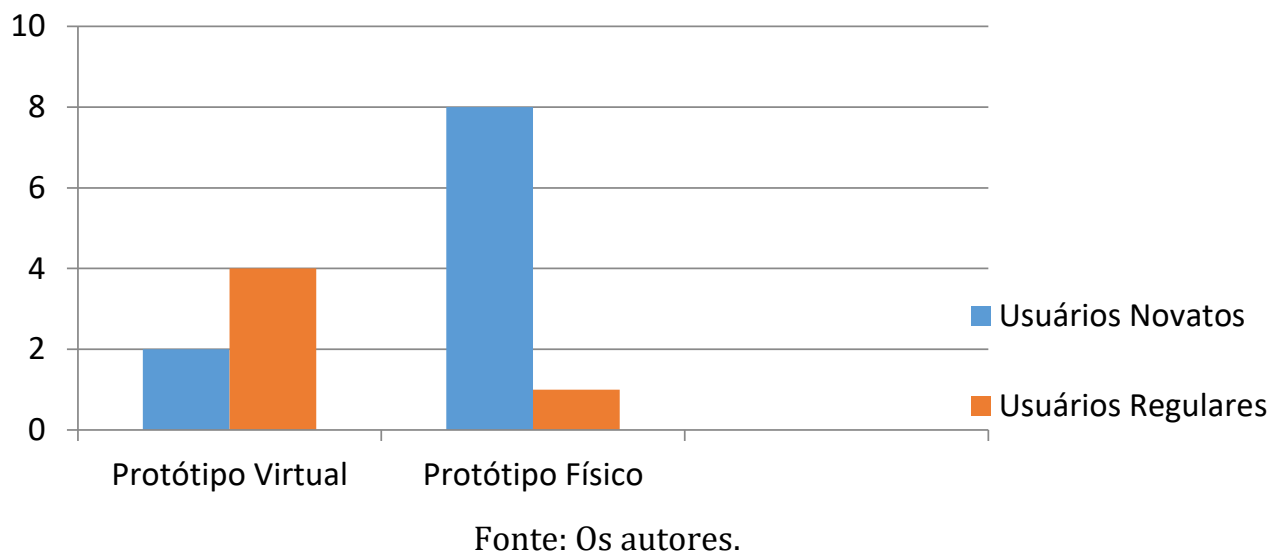

No entanto, é importante considerar que no grupo de usuários regulares a escolha pelo protótipo virtual prevaleceu. Provavelmente, a falta de experiência dos usuários novatos com o ambiente virtual pode ter influenciado na escolha pelo protótipo físico, enquanto que com os usuários regulares este fator não ocorreu.

$\mathrm{Na}$ questão seguinte, os participantes indicaram a razão pela preferência de sua escolha. Para facilitar a análise dos resultados, apenas uma das respostas poderia ser escolhida, sendo esta a que mais predominou na escolha. A última opção permitia ao usuário acrescentar outra possiblidade de resposta. 
No grupo de usuários novatos, a escolha pelo protótipo físico foi motivada pelos seguintes fatores, seguidos pelo número de participantes em parênteses: Facilidade para desempenhar a tarefa (3); Fácil compreensão do design (4) e Interessante (1). Por outro lado, os que optaram pelo protótipo virtual foram motivados pelos fatores: Fácil compreensão do design (1) e Interessante (1).

No grupo de usuários regulares, a escolha pelo protótipo virtual foi motivada pelos fatores: Facilidade para desempenhar a tarefa (1); Fácil compreensão do design (2) e Outras: Possibilidade de anexar mais elementos que no físico (1), como por exemplo, o display digital. 0 único usuário que optou pelo protótipo físico foi motivado pela facilidade de desempenhar a tarefa. Ao analisar as respostas desta questão, foram identificados dois importantes fatores:

- A experiência prévia do usuário com o ambiente virtual permitiu uma melhor compreensão do design do protótipo virtual, inclusive sugerindo outras possibilidades de avaliação da usabilidade, conforme a indicação para avaliar o display.

- O usuário que ainda não está habituado ao ambiente virtual, sente maior segurança quando consegue manusear o produto e avaliar as suas configurações a partir de um produto físico.

Contudo, a observação dos resultados sob a perspectiva da experiência do usuário com o ambiente virtual, não descarta a hipótese levantada tanto na revisão de literatura como nos resultados do questionário, da qual o protótipo físico oferece maior vantagem na interação com o usuário e melhor fidelidade às dimensões reais do objeto.

Por fim, na avaliação pós-teste, os participantes avaliaram os procedimentos do teste. Os resultados apontaram que os mesmos não tiveram dificuldades em acompanhar as etapas da pesquisa. A Figura 11 apresenta os resultados obtidos.

Figura 11: Resultado da comparação entre protótipos quanto a eficiência na avaliação sugerida na pesquisa.

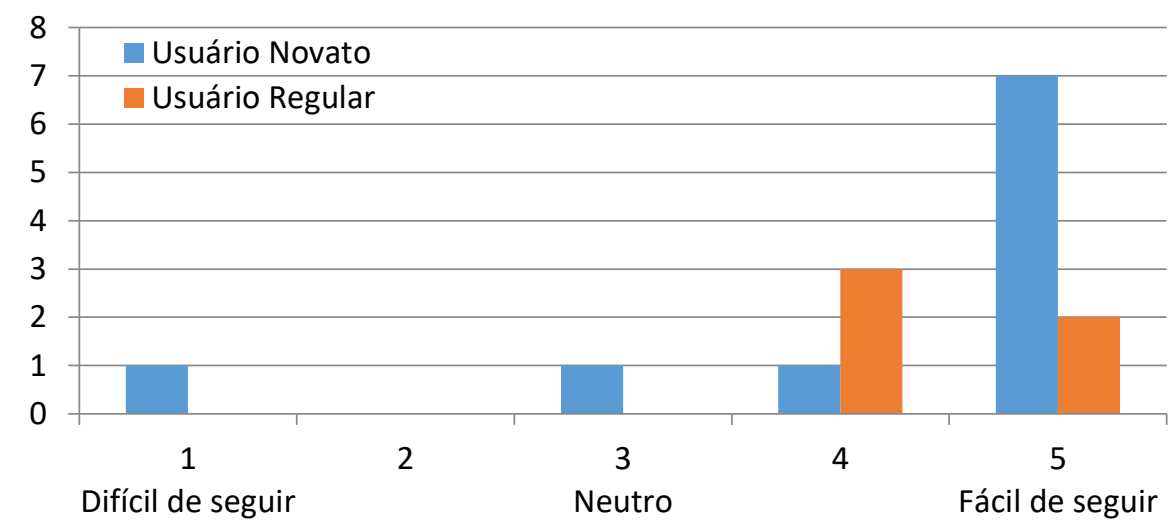

Fonte: Os autores. 


\subsection{Considerações sobre o experimento}

Com base nas respostas dos participantes, foi possível identificar a viabilidade e utilidade do ambiente virtual, utilizando a tecnologia da prototipagem virtual e prototipagem rápida ainda nas primeiras fases de desenvolvimento do produto. 0 experimento trouxe propostas de utilização de recursos acessíveis ao designer, por representar uma fase de estudo que requer investimentos a baixo custo.

O experimento realizado com os estudantes da graduação de Design teve uma importância fundamental para traçar um panorama mais integral sobre o uso das tecnologias abordadas, pois que, além de serem usuários em potencial do produto, também trouxeram o conhecimento da área do Design para contribuir na avaliação dos recursos utilizados no experimento. Como por exemplo, podemos citar as contribuições quanto ao acabamento do protótipo físico e os problemas de contraste dos textos indicativos dos botões.

Conforme descrição dos resultados, apesar dos recursos de avaliação estarem limitados a uma plataforma iPad, os participantes conseguiram interagir com o protótipo virtual e apontar alguns dos problemas de usabilidade do rádio relógio, respondendo às duas questões da pesquisa descritas no item 3. Por fim, com base nos resultados, os testes com protótipos virtuais podem ser utilizados pelo designer como uma ferramenta em potencial para a avaliação da usabilidade, pois permitem ao usuário ficar envolvido com a atividade de avaliação e gerar conhecimento significativo para a atividade de design do produto.

\section{CONCLUSÃO}

A princípio os protótipos virtuais consistiam apenas em uma visualização realística do produto, no entanto, os recentes estudos apontados neste artigo demonstraram diversas possibilidades de interação com os mesmos. Desta forma, protótipos virtuais são construídos para permitir a interação com o usuário desde o início do processo de desenvolvimento do produto, no que significa que os usuários são capazes de tocar, mover, manipular e operar os produtos virtuais através dos vários sentidos.

Em consequência desta nova prática, o número de protótipos físicos construídos durante todas as fases do processo de desenvolvimento do produto pode reduzir consideravelmente, se comparado ao uso dos protótipos virtuais, pois estes possibilitam um número maior de variações e interações. A interação somente com protótipos virtuais também é possível em consequência do desenvolvimento de tecnologias emergentes, tais como a tecnologia da Realidade Virtual, permitindo uma visão mais realista e de alta fidelidade, com representação em tempo real do modelo virtual do produto.

Contudo, conforme apresentado ao longo do artigo, os testes com produtos podem ser realizados tanto com protótipos virtuais como com físicos e ambos possuem benefícios e limitações. Para um melhor aproveitamento das 
duas ferramentas, a integração ou combinação entre eles pode ser uma opção mais eficiente.

Desta forma, os resultados obitidos a partir do estudo comparativo entre protótipos contribuiu de forma valiosa para a consolidação da ferramenta de prototipagem virtual, sendo possível destacar como pontos principais:

1. Tanto o protótipo virtual como o físico possuem vantagens e limitações na avaliação de produtos e que os dois tipos de tecnologia têm um importante papel para o design, não apresentando até o momento, a necessidade de a prototipagem virtual substituir completamente a física.

2. Os testes em ambiente virtual pelo fato de ser uma tecnologia emergente ainda não foi explorada de forma abrangente. A pouca experiência, ou mesmo nenhuma, de alguns participantes indicam a necessidade de se intensificar as pesquisas nesta área.

\section{REFERÊNCIAS BIBLIOGRÁFICAS}

BARBIERI, L.; ANGILICA, A.; BRUNO, F.; MUZZUPAPPA, M. Mixed prototyping with configurable physical archetype for usability evaluation of product interfaces. Computers in Industry 64: 310-323. 2013.

BEAUDOUIN-LAFON, M.; MACKAY, W. Prototyping Tools and Techniques. In A. Sears \& J. Jacko (Eds.). The Human-Computer Interaction Handbook: fundamentals, envolving technologies and emerging applications. Lawrence Erlbaum Associates. 2003. P. 1006-1031

BINNARD, M. Design by Composition for Rapid Prototyping. Kluwer Academic Press, Boston Massachussetts. 1999.

BORDEGONI, M.; CUGINI, U.; CARUSO, G.; POLISTINA, S. Mixed prototyping for product assessment: a reference framework. International Journal on Interactive Design and manufacturing, 3: 177-187. 2009.

BORDEGONI, M; FERRISE, F. Designing interaction with consumer products in a multisensory virtual reality environment. Virtual and Physical Prototyping, 8 (1): 51-64. 2013.

CAMPBELL, R.; GIBSON, I.; GAO, Z. A comparative study of virtual prototyping and physical prototyping. International Journal of Manufacturing Technology and Management 4(6): 503-522. 2004.

JIMENO, A.; PUERTA, A. State of the art of the virtual reality applied to design and manufacturing processes. The International Journal of Advanced Manufacturing Technology. Vol. 33: 866-874. 2007.

LIU, B. Integration of physical and virtual prototyping. PhD Thesis. Loughborough University. 2011. 
MACEFIELD, R. How to specify the participant group size for usability studies: A practitioner's guide. Journal of Usability Studies 5 (1), November 2009: 34-45.

PREECE, J.; ROGERS Y.; SHARP H. Interaction Design: Beyond HumanComputer Interaction. John Wiley \& Sons Inc. 2002. ISBN 0-471-49278-7.

SISCA, S.; MORGAN, G. \& SUBRIN, K. Virtual and Real Testing of Products. In: D. Talabã \& A. Amditis (eds.). Product Engineering: Tools and Methods Based on Virtual Reality. Springer Science + Busines Media, p. 449-460. 2008.

ULRICH, K.; EPPINGER, S. Product design and development. New York: McGraw-Hill/Irwin. 2008.

VASCONCELOS, C. S. F. A usabilidade e as tecnologias emergentes no desenvolvimento de produtos de consumo: uma abordagem em ambientes virtuais e neurociência. 326f. Tese (doutorado) - Universidade Federal de Pernambuco. CAC. Design, 2015.

WANG, G. Definition and review of virtual prototyping. Journal of Computing and Information Science in Engineering 2 (3): 232-236. 2002.

ZORRIASSATINE, F.; WYKES, C.; PARKIN, R.; GINDY, N. A survey of virtual prototyping techniques for mechanical product development. Proceedings for the Institution of Mechanical Engineers, Part B: Journal of Engineering Manufacture, 217 (4): 513-530. 2003.

\section{AGRADECIMENTOS}

À Coordenação de Aperfeiçoamento de Pessoal de Nível Superior (CAPES) pela concessão de bolsa de estudos aos pesquisadores. 